\title{
A Model to Guide Practitioners Through the Process of Collaborative Projects
}

\author{
John Raven \\ Higher Colleges of Technology, UAE \\ Learning and Teaching in Higher Education: Gulf Perspectives \\ Vol 3 No 1, January 2006
}

\begin{abstract}
Collaborative projects are often touted as an effective pedagogical practice particularly when authentic tasks and a student centred approach are involved. By default such practices often include many other aspects that need to be taken into consideration such as interdisciplinary tasks, technology or second language learning (ESL). Approaches to teaching/ learning like these are necessarily complex and a theoretical framework that unravels the numerous issues embedded is needed to understand what exactly is going on. In this paper a model developed originally by Webb and Palincsar (1996) is used to illustrate the multitude of influencing factors involved in a large scale integrated collaborative project at Sharjah Women's College. From the students' perspectives, issues related to tension with using technology and lack of transfer between disciplines was uncovered implicating the need for changes to aspects of the project.
\end{abstract}

\section{Why collaborative projects?}

Student-centred and non-traditional approaches to teaching and learning often incorporate group projects as a method for allowing students to negotiate meaning and solve problems collaboratively through discourse rather than relying on "more authoritative" teachers to provide static information (Cazden, 2001, p. 111). Discourse between students, supplemented by conversations with others such as teachers, is a key source of learning within collaborative learning practices. Because collaboration involves conversations between peers, Hoekje points out that group work is often the "participant structure of choice" in both ESL and content classrooms (1993, p.4). The technique is time proven and has much support from a wide variety of perspectives. As Kinsella noted, "In addition to promoting cognitive learning and interactional skills, group work affects student attitudes and interpersonal relationships"(1996, p.24).

Collaborative group projects often support an authentic approach to learning in that the participants can work together in a "socially situated" sense similar to that found in the "ordinary practices of the culture", that is, within everyday working and sociocultural activities (Clayden , 1994, p.166). In this manner, ill-defined problems such as those found in the workplace can be addressed by groups or teams, and inevitably such group tasks also lend themselves to interdisciplinary approaches (Klein, 1999). Joint learning activities can also be supported by technology with the advent and development of groupware and other on-line virtual collaborative tools (see Ahern \& El-Hindi, 2000, Emelo \& Francis, 2002, for example). Overall, collaborative learning approaches have much potential for creating rich learning environments and it appears that they should be encouraged.

However, implementing successful collaborative group projects is complex, especially when they involve relatively unstructured interdisciplinary tasks, second language issues and technology. There are many issues to consider. Cazden, for instance, illustrates the variety of roles that individuals working together can take on in joint learning environments including tutoring activities, critiquing each others work and sharing tasks collaboratively (2001, p.111). Gender issues and cultural norms can also impact group work particularly in contexts such as the Middle East where practices, "should be designed to reflect national culture and values" (Al Suwaidi, 1999, p. 332).

Adding integration across different courses or disciplines as well as the necessity to collaborate with computer tools add further complexity to this picture. The support for using an interdisciplinary approach at tertiary level in education is based on the view that most authentic problems cross discipline boundaries. As Seabury points out, "effectively addressing issues such as world hunger or AIDS demands that people bring insights from multiple disciplines as well as wide-ranging skills of engagement, thinking and values clarification" $(1999$, p. 6). That is, interdisciplinary, or 'integrated' learning, as it is termed in the context of the present study, typically addresses ill-defined authentic problems (see Clayden, 1994). There are no set pedagogies that make up such integrated learning but as Klein points out, "innovative approaches that promote dialogue and community, higher order critical thinking, and problem solving are common; they also tend to be student centered" (1999, p. 17). By challenging the constraints of traditional disciplines, this approach supports active learning strategies, often using teams or groups.

However, in a language learning environment the learner's limited language competence may impede their ability to conceptualize and articulate cross-disciplinary issues particularly in group work. Slimani-Rolls, for instance, in a recent study of group work with ESL students, identifies problems such as students not speaking in the target language, off task behaviour, and non participation (2003, pp. 224-5). Freeloading effects are very common in group work, especially when 
the reward structure is not geared to avoid this (see Slavin, 1996). Davis and Ralph in a study of on-line collaboration noticed the same thing with low levels of participation using virtual collaborative tasks (2001, p.217). In many groups the discourse goes off task or becomes destructive rather than constructive; power issues can intrude, particularly when there are differences in language/cultural proficiency between group members (Leki, 2001). While the interdisciplinary approach supports authentic learning within groups, it adds further complexity to an already complex process particularly for language learners.

The use of computers in language learning contexts can be viewed as a cross-disciplinary component in that "technical skills" are often added to the learning mixture (Healey \& Klinghammer, 2002, p. 3). Computers, as tools used for constructing projects, play a central mediating role as well as being a potential source of conflict within groups. The problem is that, although personal computers (PCs) are very versatile in terms of what they can be programmed to do and how they can be networked to other broader systems, they were not designed to be physically shared. Crook observes that joint activity with computers can be thought of in terms of, "physical activity at, or around a computer, activity through a computer, or activity in relation to a computer" (Crook, 1999, p. 110 italics in original). However used, they are a personal device designed for a single user, whereas learning is generally a social enterprise. Salaberry, for example, concluded following a review of the use of computers with ESL learners, that

whereas most 'new technologies' (radio, television, VCR, computers) may have been revolutionary in the overall context of human interaction, it is not clear that they have achieved equal degrees of pedagogical benefit in the realm of second language teaching (2001, p. 39).

One of Salaberry's key concerns is with the "efficient use of human and material resources" (2001, p. 39). The use of technology can create tension in a collective educational language learning context particularly where students need to share project work among separate computers. The type of assistance, or mediation, provided by a computer is much different from that provided by other people (see Cazden, 2001, p. 109). Indeed authentic projects involving technology tend to be chaotic in that, as Fielden observes, "the move towards self-responsibility inevitably brings with it chaotic situations as outside control is relaxed" (2000, p. 106).

With consideration of these issues, collaborative group activity does not always work effectively. So, how do we, as practitioners, avoid these problems? Is there a model for implementing group projects that takes these issues into account, and that has clear guidelines for practitioners to follow? The remainder of this paper discusses such a model, and an attempt to apply it to a specific interdisciplinary group work project.

\section{The IPO Model}

Theories of group process are commonly divided into two broad psychological perspectives generally described as the motivational and cognitive learning models (Abrami \& Chambers, 1996; Slavin, 1996; Webb \& Palincsar, 1996). Hedegaard comments that this distinction can also be envisaged as a difference between affective, "hot" paradigms and rational, "cold" ones, reflecting the research concerns of both genres (Hedegaard, 2002, p. 55). In other words, group work research tends to focus upon two different types of questions that researchers typically ask about groups, namely: Are the students active and motivated? How exactly does group work lead to better learning? These perspectives describe a broad dichotomy between 'why?' and 'how?' theories that broadly divide the literature into two camps that explain the basic mechanics of group work yet do little to enlighten practitioners in the field as to specific practices. Group work is far more complex than this.

A more comprehensive approach was developed by Webb and Palincsar (1996) to encompass the complexity of issues and numerous contributing factors in group work. These authors examined the wide variety of influences upon joint activity in a meta-study and suggested that these can be represented by the Input-Process-Outcome (IPO) model depicted below:

Figure One: The Input-Process-Outcome model of group processes (Webb \& Palincsar, 1996, p. 851, bold text in original). 


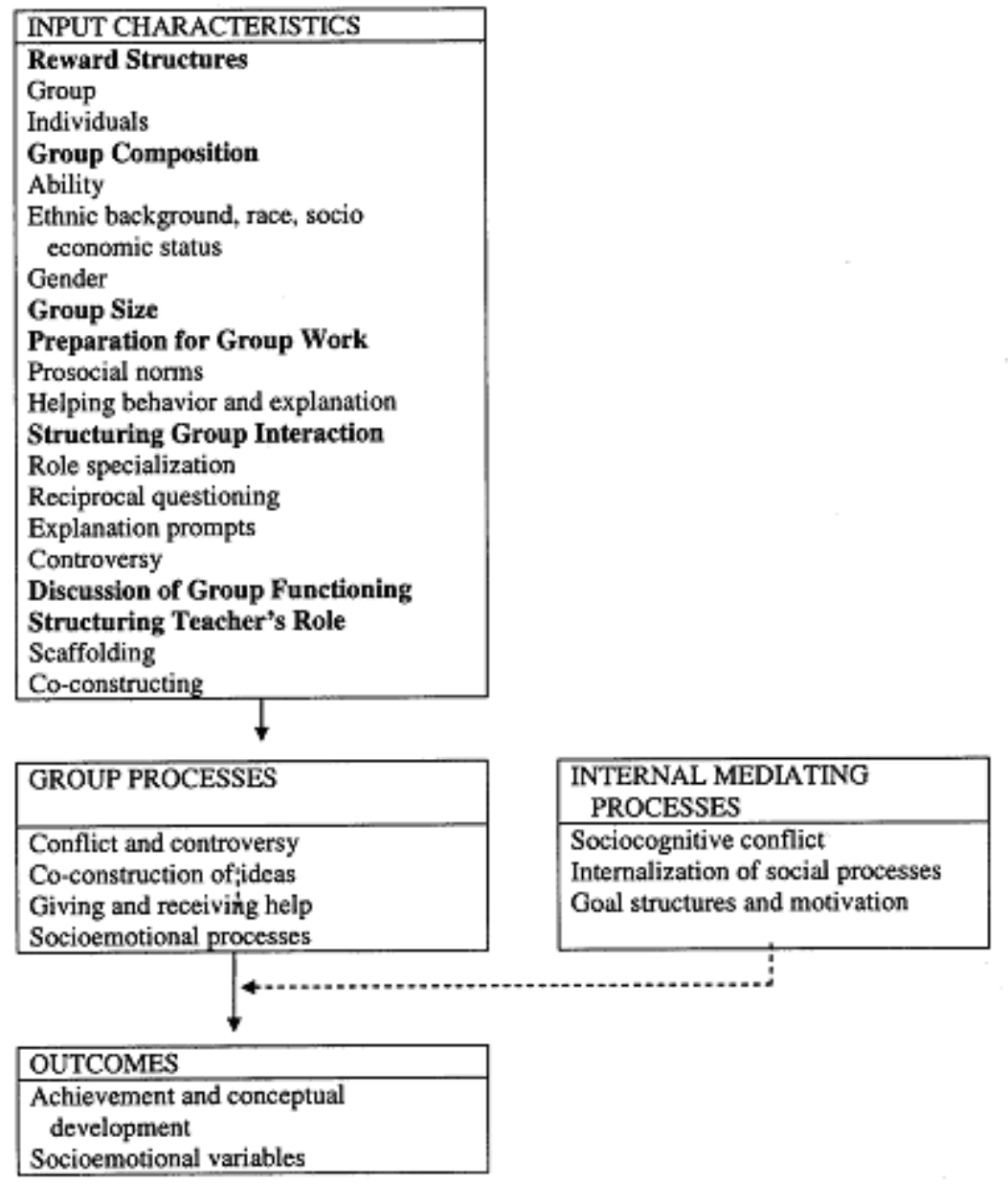

The motivational and cognitive learning perspectives are grouped together in the IPO model as internal mediating processes, a point of view that bypasses the dualistic split in the literature and highlights these two factors instead as complimentary psychological influences. The model also lists numerous other factors that potentially influence group process, including those that can appear during group formation. These are grouped into areas and include issues related to group composition such as gender, ability, language and culture: factors that are recurring issues in the Middle East. Other input characteristics concern contextual factors such as how the interaction in the groups is structured with or without the role of the teacher and reward structures. Influences related to group process are also listed in the model and include consideration of any tension that may occur during the co-construction of a joint project by sharing resources which would include tension related to the sharing of computer resources. Outcome factors listed by the IPO model include both learning outcomes, as measured by academic grades for outputs from the activity, as well as socio-emotive outcomes including whether the students enjoyed the activity. This is a framework, therefore, that neatly encapsulates the complexity of implementing intricate pedagogies such as integrated collaborative project work and that also indicates the level of orchestration required.

Webb and Palincsar based the IPO model upon a metastudy of research on group learning. This included consideration of some of their own work upon the co-construction of knowledge through elaborated help as well as hundreds of other studies at the time on various aspects of joint learning (1996, see pp. 851-866). Their discussion of Kagan's (1992) cooperative learning genre that focuses primarily upon reward structures and individual accountability, for example, still applies to studies conducted in the motivational tradition. Current research on collaborative learning, such as Rogoff, Turkanis, and Bartlett's (2001) concerns for building collaboration through a sense of community, which illustrates cultural factors and the internalisation of social processes, speaks directly to key features of the IPO model. The rest of this paper describes a group project from Sharjah Women's College (SWC), using the IPO model as a framework for discussion:

\section{The Context: Input Characteristics}

Input Characteristics, as listed in the IPO model, include consideration of a wide range of influences within the context in which the group activity is taking place. In this example these are addressed through a discussion of the context of the project, some features of the individuals involved, group formation and details of the collaborative task.

The collaborative project took place at Sharjah Women's College, a post-secondary government college in the UAE that only caters for Emirati students and where the language of instruction is English. The study focussed on seven sections of Diploma students enrolled in the IT program in their third semester during the 2004/5 academic year. The students were all females in the 17-19 year age range and all of the students were taking the same four courses: English (ESL), Customer Care, Software Applications I and Internet Information Access. They were a homogeneous group in terms of 
ethnic background, gender, race, social norms and, to a large extent by virtue of the placement process at HCT, academic ability.

In general, the students were accustomed to traditional routine learning and memorisation, having experienced government secondary schools, institutions that are increasingly under pressure to reform teaching/ learning methodologies (see Al Sulayti, 1999, p.272). In addition, the English course that the students were involved with was centred upon preparing the students for the Preliminary English Test (PET), a standardized intermediate level English competency test (see University of Cambridge, 2005). In this semester, the students were required to achieve up to band level 4 towards the PET exams. In other words, the English program at this level provides an example of a curriculum focused on traditional "high-stakes" testing common in the Gulf region (see Syed, 2003). In this sense, all the students had a shared knowledge and experience of educational techniques which tended away from 'modern' techniques such as collaborative learning, and which relied predominantly on teacher-centred tasks and individual memorisation.

The teaching team for this semester decided to integrate all four courses in a single project staggered over the last six weeks of the semester via an authentic group project. From an English learning perspective, it provided a rare opportunity to apply the skills learned in the PET-orientated class in an authentic but guided way (note however that the English marks awarded for the project were completely independent of the externally moderated PET exam). The project also enabled the team to incorporate non-traditional activities into the courses, including teamwork and interdisciplinary exploration. It was initiated in the Customer Care course when the students were placed in groups to carry out a series of tasks to simulate a typical business environment. In this sense the projects were authentic. The groups were self selected, although some teachers assisted with this process when groups did not naturally form. Because language competence was a major factor, all instructions and information given to students for the project was checked by English teachers for appropriate level as an integral part of the projects.

The task was structured to enable easy division of tasks between group members, and to identify the teacher's role. As part of the Customer Care and Computer Applications courses, each group was required to create sample correspondence for their chosen company such as product advertisements, sample letters, logos, faxes and emails. Primary research about the business was then carried out by the groups using computer tools from the Software Applications class. They created a survey, collected data and analyzed the results using a spreadsheet program. The project finished with group presentations to the teachers of a website constructed for the company with skills learned within the Internet Information course, along with a supporting report. As part of the integration, marks were discussed by the teachers and agreed upon following each presentation. To give an idea of how integration was achieved, the table below summarizes the assessments allocated to the project by each course and therefore the academic reward structure. As part of the integration, marks were discussed by the teachers and agreed upon following each presentation with consideration of the supporting documentation given. It was a collaborative effort by both faculty and students.

Table1: Integrated assessment structure

$\begin{array}{llc}\text { Course } & \text { Project Assessment } & \begin{array}{c}\text { Percentage of each } \\ \text { course }\end{array} \\ \text { English } & \text { Communication skills. } & 5 \% \\ \text { Customer Care } & \begin{array}{l}\text { Created and administered a survey. Created company30\% } \\ \text { documentation, leaflets, catalogue, logo etc... using MS } \\ \text { Word. }\end{array} \\ \text { Software Applications I I } & \begin{array}{l}\text { Created a report in MS Word including Excel spreadsheet25\% } \\ \text { charts and statistics. Created and gave a presentation using }\end{array} \\ \text { PowerPoint. } & \\ \text { Internet } & \text { Information Website creation using MS FrontPage and with supporting } 30 \% \\ \text { Access } & \text { documentation. }\end{array}$

\section{Processes}

This aspect of the IPO model is concerned with the dynamic activity that is taking place within each of the groups including conflict, co-construction of ideas and socio-emotional responses, such as how well the students coped with these dynamics. These concerns were addressed in this study by observation of the groups and via a post-project questionnaire. A total of 120 students from the seven sections involved completed the anonymous survey, which was given out at the beginning of the following semester to reduce any grade- or teacher-related bias. The survey comprised seven questions. Two questions in the survey asked the students what they liked and did not like about the projects. Another question asked the students whether they had any problems sharing the work between computers. These questions were intended to uncover any tensions as well as general perceptions of the group work that took place.

The written responses were grouped according to topics mentioned. The majority of the written responses to the first question $(n=119)$, for instance, were positive comments regarding teamwork (70 comments). One student wrote "I like to work in a team and learn how we use the information from the Internet and learn new words". As indicated by this comment, many students also mentioned that they enjoyed using computer skills (43 comments). These results reflect the students perceptions of key processes and outcomes listed by the IPO model specifically co-construction, giving and receiving help, motivational aspects and internalization of social processes.

The most negative factor listed for the question above was insufficient time (53 comments) and this was echoed by responses to another question, which asked what would make the projects better. Most of the students felt that they did 
not have enough time for the projects, even though the project spanned four classes over the last six weeks of the semester. Other concerns included dissatisfaction with how the groups were formed and also confusion with the instructions, concerns that appear to reflect on some of the input characteristics of the task rather than on group processes themselves.

Concerning computer use within the teams, however, noticeable tension with sharing computer resources was indicated by the responses with only $17 \%$ of the students reporting no problems. Indeed $84 \%$ of the students reported that they had experienced either a few, some or a lot of problems sharing computers. This illustrates one aspect of the IPO model: conflict and controversy. An analysis of how the students used the computers perhaps explains why. The students used common computer tools such as MS Word as taught within the program of study, that is, single user applications. No applications designed specifically for collaboration either in virtual or face-to-face formats were used and intra-group tension therefore resulted.

\section{Outcomes}

Possible outcomes listed by the IPO model include socio- emotional responses, academic achievement and conceptual development. Some of the socio-emotional responses were revealed above in the discussion concerning what the students liked and did not like about the projects after they had finished. Generally there was a positive perception regarding teamwork but some frustration concerning time constraints. The academic results were very positive, with just about all of the groups passing the project, but this evidence alone gives little insight into what exactly the students perceived that they learned from completing the group project. So, we asked them directly in the post-project survey. Consider the following table of results that summarize the student's responses to a question in the survey:

Table Two: How much did you learn about the following during the project?

$\begin{array}{lllll}\text { Choice } & \text { Nothing } & \text { A little } & \text { Some } & \text { A lot } \\ \text { English writing skills } & 1 \% & 14 \% & 52 \% & 34 \% \\ \text { English reading skills } & 4 \% & 19 \% & 36 \% & 41 \% \\ \text { English speaking skills } & 2 \% & 10 \% & 33 \% & 55 \% \\ \text { Computer skills } & 1 \% & 3 \% & 18 \% & 78 \% \\ \text { Teamwork skills } & 1 \% & 8 \% & 24 \% & 68 \%\end{array}$

The results of this survey reveal some very positive perceptions of the learning that took place within the project generally. The students $(n=120)$ predominantly ticked the "A lot" column across most categories. However, there was a noticeable difference between responses to the three categories related to English language skills and the other two categories concerning computer skills and teamwork. Simply stated, the students did not perceive that they learned as much about English skills as they did about computer skills and teamwork. Indeed most of the students felt that they only learned "a little" or "some" about English reading and writing skills during the project even though all of the activities employed these skills. This is surprising considering the large support for using collaborative group techniques with second language students discussed earlier (see Kinsella, 1996, for example), and implies that, from the students perceptions, the English skills used in the collaborative projects distracted from rather than supported the English curriculum which, as discussed earlier, was preparing the students towards PET examinations. This example may then provide an example of tension between what Cazden (2001) refers to as traditional and non traditional teaching approaches.

\section{Implications and conclusion}

The feedback from the students was very positive concerning teamwork and computer skills yet revealed the perception that English skills were not utilized as much for this particular project. The fact that the English part of the project was only worth $5 \%$ of the English course could be a contributing factor. The implication is that the students had more difficulty seeing the link between the group task and the English Course than with the other three courses. Reasons for this could be the perceived relevance of the group exercise towards the English curriculum and perhaps upon interference with preparation towards the PET exam. This finding conflicts with our observations that the projects were English intensive in terms of applying reading, writing and speaking skills, and suggests that it is the students' awareness rather than the quantity and quality of the English content applied in the projects that was lacking. More emphasis should, therefore, have been placed on raising the student's awareness and the value of their English language learning in this particular context. On this point van Lier suggests that,

We must educate the students to make their own decisions increasingly, and in order to do that we must make sure that they know what they are doing. Eventually they are best served by being able to regulate their own language learning (1994, p 70).

One way to implement this in the context of the group projects would have been to have placed more emphasis on soft skills as the link between technology and English skills. The Customer Care course includes separate assessments on communication skills such as effective telephone and email etiquette. These should have been included in this project as well as other appropriate English language skills in addition to the presentations and documentation created by the 
students. By raising the students' awareness of using English to help people use technology effectively, such as in the case of managing a helpdesk, for example, or answering the telephone correctly, links between learning the language and real world applications would be more apparent to them.

Tension with physically sharing computer technology was reported by many students, as were difficulties with meeting time constraints. The two findings are linked, I believe, as the students had ample time for the project, which then points to inefficient use of computer tools within each team. Even though the majority of students wrote that they liked the teamwork involved in the project, in response to the question: What would make the project better? many students then wrote: "Work together". This seemingly contradictory finding illustrates the issues with sharing computers that many groups experienced and implies that more appropriate software may be better suited to these types of projects, a point that I have made elsewhere (Raven, 2005) and one that is supported by the literature (see Crook, 1999). Projects should specify what rather than how tasks need to be completed (see Nurinmen \& Tuomisto, 2000). In this context very specific instructions were given regarding the applications that should be used to create the deliverables for each phase of the project. The implication is that this strategy should be de-emphasized, that the groups need to have an array of computer tools, including opportunities for virtual collaboration via forums, for example, from which they choose to construct the required outputs for the project.

Implementing and managing collaborative group projects that involve presenting authentic problems to groups of second language learners and that also require them to use technology has been discussed in this paper as a complex, if not chaotic pedagogical approach. With so many balls balancing in the air it is important to get the balance right, and the first step suggested in this paper is to try to understand the many facets involved. In this paper I have used the IPO model to help unravel and describe the various issues to take into an account when implementing a collaborative group project, and have used an example from Sharjah Women's College to illustrate this. The purpose of this paper was not to justify or "sell" one particular practice but rather to point out one method for managing the complexity of issues that should be taken into account when implementing collaborative group project strategies. The IPO model is suggested here as a useful framework to use by practitioners for enhancing their understanding and implementation of a very well proven educational technique.

There is also a need, based on the results of this study, for more research on the tensions between external testorientated second language curricula and the successful implementation of modern pedagogical methodologies such as authentic projects and collaborative group work from a student learning point of view. To what extent do the two work against each other?

\section{References}

Abrami, P. C., \& Chambers, B. (1996). Research on cooperative learning and Achievement: Comments on Slavin. Contemporary Educational Psychology, 21, 201-210.

Ahern, T. C., \& El-Hindi, A. E. (2000). Improving the instructional congruency of a computer-mediated small-group discussion: A case study in design and delivery. Journal of Research on Computing in Education, 32(3), 385-401.

Al Sulayti, H. (1999) Education and Training in GCC Countries: Some Issues of Concern. In Education and the Arab World, (pp:271-278), The Emirate Center for Strategic Studies and Research, Abu Dhabi

Al Suwaidi, J. S. (1999) Education and Human Resources Development in the Gulf: Challenges for the Twenty-First Century. In Education and the Arab World, (pp:331-

333), The Emirate Center for Strategic Studies and Research, Abu Dhabi

Cazden, C. (2001). Classroom Discourse: The Language of Teaching and Learning. Portsmouth, N.H. Heinemann. Clayden, E. (1994). Authentic activity and learning. British Journal of Educational Studies, 42(2), 163-173.

Crook, C. (1999). Computers in the community of classrooms. In K. Littleton \& P. Light (Eds.), Learning with Computers: Analysing Productive Interaction (pp. 102-117).

London: Routledge.

Davis, M., \& Ralph, S. (2001). Stalling the Learning Process: Group Dynamics in Cyberspace. Studies in the Education of Adults, 33(2), 217-230.

Emelo, R. Francis, L. M. (2002) Virtual Team Interaction, Training and Development, 56(10), pp: 17-20

Fielden, K. (2000) Balancing at the Edge of Chaos in a Sociotechnical World. In E. Coakes, D. Willis \& R. Lloyd-Jones

(Eds.) The new sociotech : graffiti on the long wall (pp. 106-115) London, UK. Springer-Verlag.

Healey, D. \& Klinghammer, S.J. (2002) Constructing Meaning with Computers, Tesol Journal, 11(3), 3

Hedegaard, M. (2002). Learning and child development: A Cultural-Historical Study. Aarhus University Press.

Hoekje, B. (1993) Group Work, the Teacher's Role, and the Student-Centered Classroom, TESOL Journal, 3(2) pp: 4- 6. 
Kagan, S. (1992). Cooperative Learning (8th ed.). San Juan Capistrano, C.A.: Resources for Teachers.

Kinsella, K. (1996) Designing Group Work That Suports and Enhances Diverse Classroom Work Styles, TESOL Journal, 6(1), pp: $24-30$

Klein, J. T. (1999). Mapping Interdisciplinary Studies. Washington DC: The Association of American Colleges and Universities.

Leki, I. (2001). "A Narrow Thinking System": Nonnative-English-Speaking Students in Group Projects Across the Curriculum. TESOL Quarterly, 35 (1) $39-67$.

Nurminen, M. I. \& Tuomisto, A. K. (2000) Stop Information Technology from Undermining Group Autonomy! In E. Coakes, D. Willis \& R. Lloyd-Jones (Eds.) The new sociotech : graffiti on the long wall (pp. 208-219) London, UK. Springer-Verlag.

Raven, J (2005) How not to integrate computers with group projects: An example from the field. Technology, Pedagogy and Education. 14(2). 257-269.

Rogoff, B., Turkanis, C. G., Bartlett, L. (2001) Learning together : children and adults in a school community. New York : Oxford University Press

Salaberry, M. R. (2001) The Use of Technology for Second Language Learning and Teaching: A Retrospective. The Modern Language Journal, 85(i), 39-56

Seabury, M. B. (1999). Interdisciplinary General Education: Questioning outside the lines. N.Y.: The College Board.

Slavin, R. E. (1996). Research for the future: research on cooperative learning and achievement: what we know, what we need to know. Contemporary Educational

Psychology, 21, 43-69.

Slimani-Rolls, A. (2003) Exploring a world of paradoxes: An investigation of group work.. Language Teaching Research 7(2), 221-39

Syed, Z. (2003) TESOL in the Gulf: The Sociocultural Context of English Language Teaching in the Gulf. TESOL Quarterly, 37(2), 337-340

University of Cambridge (2005). ESOL Examinations. Retrieved June 15, 2005, from http://www.cambridgeesol.org/exams/pet.htm

van Lier, L. (1994) Language awareness, contingency, and interaction. In J. Hulstijn \& R. Schmidt (eds.) Consciousness in Second Language Learning: AlLA Review, 11 $69-82$.

Webb, N., \& Palinscar, A. S. (1996). Group processes in the classroom. In D. C. Berliner \& R. C. Calfee (Eds.), Handbook of Educational Psychology (pp. 841-873).

New York, N.Y. Prentice- Hall. 